\title{
BMJ
}

\section{Body piercing in England: a survey of piercing at sites other than earlobe}

\author{
Angie Bone, specialist registrar in public health medicine, ${ }^{1}$ Fortune Ncube, consultant epidemiologist , \\ Tom Nichols, statistician , ${ }^{1}$ Norman D Noah, professor of public health ${ }^{2}$
}

\begin{abstract}
${ }^{1}$ Centre for Infections, Health Protection Agency, London NW9 5EQ

${ }^{2}$ London School of Hygiene and Tropical Medicine, London WC1E 7HT

Correspondence to: A Bone, South West London Health Protection Unit, Lupin Ward, Jasmine Tower, Springfield Hospital, London SW17 7DJ abone@nhs.net
\end{abstract}

doi:10.1136/bmj.39580.497176.25

\section{ABSTRACT}

Objectives To estimate the prevalence of body piercing, other than of earlobes, in the general adult population in England, and to describe the distribution of body piercing by age group, sex, social class, anatomical site, and who performed the piercings. To estimate the proportion of piercings that resulted in complications and the proportion of piercings that resulted in professional help being sought after the piercing.

Design Cross sectional household survey.

Setting All regions of England 2005.

Participants 10503 adults aged 16 and over identified with a two stage selection process: random selection of geographical areas and filling predefined quotas of individuals. Results weighted to reflect the national demographic profile of adults aged 16 and over.

Main outcome measures Estimates of the prevalence of body piercing overall and by age group, sex, and anatomical site. Estimates, in those aged 16-24, of the proportion of piercings associated with complications and the seeking of professional help.

Results The prevalence of body piercing was 1049/10 503 (10\%, 95\% confidence interval $9.4 \%$ to $10.6 \%$ ). Body piercing was more common in women than in men and in younger age groups. Nearly half the women aged 16-24 reported having had a piercing $(305 / 659,46.2 \%, 42.0 \%$ to $50.5 \%$ ). Of the 754 piercings in those aged $16-24$, complications were reported with 233 (31.0\%, 26.8\% to $35.5 \%)$; professional help was sought with 115 (15.2\%, $11.8 \%$ to $19.5 \%$ ); and hospital admission was required with seven $(0.9 \%, 0.3 \%$ to $3.2 \%)$.

Conclusions Body piercing is common in adults in England, particularly in young women. Problems are common and the assistance of health services is often required. Though serious complications requiring admission to hospital seem uncommon, the popularity of the practice might place a substantial burden on health services.

\section{INTRODUCTION}

Cosmetic body piercing has increased greatly in popularity in recent years, but there are few data to indicate how many people have had a body piercing or how often it is performed. Complications with body piercing have often been reported in the medical and dental literature and in the media and have been debated by parliament, ${ }^{1-4}$ but there have been few attempts to quantify the problem.

Published studies in other developed countries report a prevalence of body piercing ranging from $4.3 \%$ to $51 \% .^{5-10}$ The wide variation in estimates is due to factors such as the time and location of the studies, the different population groups participating, and different definitions of piercing used. Most studies have surveyed adolescents or young adults with most using convenience samples, in which selection bias is likely to have a major influence on the findings. Three surveys of the general population provide estimates of prevalence of body piercing (excluding earlobe piercing) of between $6.7 \%$ and $14 \% .{ }^{11-13}$ Two of these were recent studies, but none of them was performed in the United Kingdom.

Estimates of the proportion of body piercings that develop complications range from $17 \%$ to $70 \%$, the variation again probably due to the different definitions used and populations studied. ${ }^{571415}$

Analysis of hospital episode statistics in England and Wales found that the annual incidence of auricular perichondritis more than doubled from 1990-1 to 1997-8. ${ }^{16}$ The rise is thought to be caused by the increasing popularity of high ear piercing - that is, in the upper third of the pinna. Of 115 general practitioners who responded to a survey in Bury and Rochdale in 1999, 95\% stated that they had seen a patient with a complication of piercing. ${ }^{17}$ Whittle and Lamden found that 62 of 64 dentists in south Lancashire had seen patients with lip or tongue piercings in the previous 12 months. ${ }^{18}$ Patients with associated oral health problems had been seen by $44 \%$ of respondents. Both surveys had response rates of around $60 \%$.

We estimated the prevalence of body piercing in England; the proportion of piercings that resulted in complications; and the proportion of piercings that resulted in complications serious enough for further help to be requested. We did this by sampling the general population of England aged 16 and over.

\section{METHODS}

We commissioned the British Market Research Bureau (BMRB) to conduct our survey using the BMRB Face to 
Face Omnibus survey (www.bmrb.co.uk/?compo nent=page\&id=755). ${ }^{19}$ The survey was carried out in January to March 2005.

The selection of adults was two stage. The first stage involved random sampling of geographical areas and the second stage the sampling of individuals to fill predefined quotas. Primary sampling units were small neighbourhoods of about 300 households. Sampling of these units was stratified and proportional across all combinations of the 10 standard regions of England and 56 ACORN types. (The ACORN type of a particular neighbourhood is based on a number of demographic statistics and lifestyle variables (www. caci.co.uk/acorn/). A total of 694 different neighbourhoods were sampled, and these were considered to be representative of neighbourhoods in England.

Within a primary sampling unit, the selection of adults was non-random. Interviewers were provided with a list of possible addresses, and quota controls were set in terms of sex, age group, and employment status. Individuals were interviewed at various times (including the evenings and weekends). Only one individual was interviewed at each address. After completing an interview, the interviewers were directed not to attempt interviews in the next or next but one house or flat.

We designed the questionnaire with the research company. A piercing was defined in the questionnaire as "an opening in any part of the body (except the earlobes) through which jewellery might be worn." We did not distinguish between piercings that were currently patent and those that had been allowed to heal over. We excluded soft earlobe piercings to achieve a larger sample size than would otherwise have been possible. Individuals were first asked "Have you ever had any body piercings - that is, NOT including any earlobe piercings?" Those who reported having ever had such a piercing were then asked a series of questions. For each of a maximum of 10 piercings recorded in the survey, the respondent was asked "Where on the body is/was the piercing?" To this they were allowed to record one of navel (belly button), tongue, nose, ear, nipple, lip, eyebrow, genital, other, and don't know. They were then asked "Which, if any, of the following health problems did you experience?" To this they were allowed to record one or more of the

\begin{tabular}{|c|c|c|c|c|c|}
\hline & No of adults surveyed* & $\begin{array}{l}\text { No of adults with one } \\
\text { or more piercings* }\end{array}$ & $\begin{array}{l}\text { Prevalence (\%) } \\
(95 \% \mathrm{Cl})\end{array}$ & $\begin{array}{l}\text { Crude prevalence ratio } \\
\qquad(95 \% \mathrm{Cl})\end{array}$ & P value \\
\hline Overall & 10503 & 1049 & $10.0(9.4$ to 10.6$)$ & & \\
\hline \multicolumn{6}{|l|}{ Sex: } \\
\hline Men & 5123 & 261 & 5.1 (4.4 to 5.8$)$ & 1 & \multirow{2}{*}{$<0.001$} \\
\hline Women & 5380 & 788 & 14.6 (13.7 to 15.7$)$ & 2.88 (2.48 to 3.35 ) & \\
\hline Men aged 16-24 & 871 & 114 & 13.1 (10.6 to 16.1$)$ & 1 & \multirow{2}{*}{$<0.001$} \\
\hline Women aged 16-24 & 659 & 305 & $46.2(42.0$ to 50.5$)$ & 3.53 (2.82 to 4.42$)$ & \\
\hline \multicolumn{6}{|l|}{ Age group (years): } \\
\hline $16-24$ & 1531 & 419 & 27.4 (24.8 to 30.0$)$ & 1 & \multirow{6}{*}{$<0.001$} \\
\hline $25-34$ & 1796 & 336 & 18.7 (17.0 to 20.6$)$ & 0.68 (0.60 to 0.78$)$ & \\
\hline $35-44$ & 2039 & 228 & 11.2 (9.9 to 12.6$)$ & $0.41(0.35$ to 0.48$)$ & \\
\hline $45-54$ & 1669 & 46 & $2.8(2.1$ to 3.6$)$ & 0.10 (0.07 to 0.14$)$ & \\
\hline $55-64$ & 1445 & 14 & $1.0(0.6$ to 1.7$)$ & $0.04(0.02$ to 0.06$)$ & \\
\hline$\geq 65$ & 2023 & 5 & $0.3(0.1$ to 0.6$)$ & $0.01(0.00$ to 0.02$)$ & \\
\hline \multicolumn{6}{|l|}{ Social grade: } \\
\hline$A B$ & 2727 & 155 & 5.7 (4.7 to 6.8$)$ & 1 & \multirow{5}{*}{$<0.001$} \\
\hline C1 & 2980 & 322 & $10.8(9.7$ to 12.0$)$ & 1.91 (1.54 to 2.37 ) & \\
\hline C2 & 2164 & 252 & 11.7 (10.4 to 13.1$)$ & 2.06 (1.65 to 2.56$)$ & \\
\hline D & 1705 & 210 & 12.3 (10.6 to 14.2$)$ & $2.17(1.72$ to 2.75$)$ & \\
\hline $\mathrm{E}$ & 927 & 110 & 11.8 (10.4 to 13.5$)$ & 2.09 (1.65 to 2.65$)$ & \\
\hline \multicolumn{6}{|l|}{ Region: } \\
\hline London & 1532 & 109 & $7.1(5.8$ to 8.7$)$ & 1 & \multirow{9}{*}{0.002} \\
\hline South east & 2404 & 248 & $10.3(9.2$ to 11.5$)$ & 1.44 (1.14 to 1.82$)$ & \\
\hline South west & 1063 & 99 & $9.3(7.6$ to 11.4$)$ & 1.31 (0.98 to 1.74$)$ & \\
\hline East Anglia & 464 & 47 & 10.1 (7.6 to 13.2$)$ & 1.41 (1.01 to 1.98$)$ & \\
\hline East Midlands & 882 & 119 & 13.4 (11.1 to 16.2$)$ & 1.88 (1.43 to 2.48 ) & \\
\hline West Midlands & 1115 & 100 & 9.0 (7.4 to 10.9$)$ & $1.26(0.95$ to 1.66$)$ & \\
\hline Yorkshire and Humberside & 1062 & 111 & 10.4 (8.3 to 13.0$)$ & 1.46 (1.08 to 1.97$)$ & \\
\hline North west & 1334 & 143 & $10.7(9.0$ to 12.7$)$ & 1.50 (1.15 to 1.95$)$ & \\
\hline North & 647 & 74 & 11.4 (8.8 to 14.7$)$ & $1.60(1.15$ to 2.21$)$ & \\
\hline
\end{tabular}

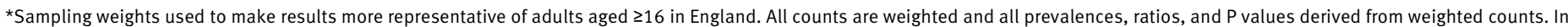

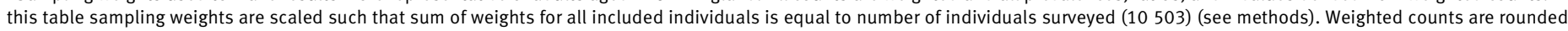
to nearest whole number. 
Table 2 | Prevalence (95\% confidence interval) of ever having had one or more piercings by specific anatomical site by sex (adults aged $\geq 16$ in England)

\begin{tabular}{|c|c|c|c|c|c|c|c|}
\hline & \multicolumn{2}{|c|}{ Adults* $(n=10503)$} & \multicolumn{2}{|c|}{$\operatorname{Men}^{*}(n=5123)$} & \multicolumn{2}{|c|}{ Women* $(n=5380)$} & \multirow[b]{2}{*}{$\begin{array}{l}\text { Crude prevalence ratio } \\
\text { for women } v \text { men; P value }\end{array}$} \\
\hline & $\begin{array}{l}\text { Piercings/ } \\
\text { pierced adult }\end{array}$ & Prevalence (\%) & $\begin{array}{l}\text { Piercings/ } \\
\text { pierced men }\end{array}$ & Prevalence (\%) & $\begin{array}{c}\text { Piercings/ } \\
\text { pierced women }\end{array}$ & Prevalence (\%) & \\
\hline Ear (not lobe) & $245 / 185$ & $1.8(1.5$ to 2.1$)$ & $84 / 66$ & $1.3(1.0$ to 1.7$)$ & $162 / 119$ & $2.2(1.8$ to 2.7$)$ & 1.71 (1.24 to 2.37 ); 0.001 \\
\hline Eyebrow & $164 / 140$ & $1.3(1.1$ to 1.6$)$ & $95 / 80$ & $1.6(1.2$ to 2.0$)$ & $69 / 60$ & $1.1(0.9$ to 1.4$)$ & 0.71 (0.51 to 1.00$) ; 0.05$ \\
\hline Nose & $368 / 316$ & $3.0(2.7$ to 3.4$)$ & $36 / 31$ & $0.6(0.4$ to 0.9$)$ & $332 / 284$ & $5.3(4.7$ to 6.0$)$ & $8.6(5.8$ to 13.0$) ;<0.0005$ \\
\hline Lip & $77 / 61$ & $0.6(0.4$ to 0.8$)$ & $31 / 25$ & 0.5 (0.3 to 0.8$)$ & $46 / 35$ & 0.7 (0.5 to 0.9$)$ & 1.34 (0.76 to 2.36$) ; 0.31$ \\
\hline Tongue & $182 / 156$ & 1.5 (1.3 to 1.7$)$ & $60 / 51$ & $1.0(0.7$ to 1.3$)$ & $122 / 105$ & 1.9 (1.6 to 2.3$)$ & 1.95 (1.38 to 2.76$) ;<0.0005$ \\
\hline Nipple & $173 / 143$ & $1.4(1.1$ to 1.6$)$ & $110 / 94$ & $1.8(1.5$ to 2.3$)$ & $63 / 49$ & $0.9(0.7$ to 1.2$)$ & $0.49(0.35$ to 0.70$) ;<0.0005$ \\
\hline Navel & $639 / 529$ & $5.0(4.6$ to 5.5$)$ & $21 / 19$ & $0.4(0.2$ to 0.6$)$ & $617 / 510$ & 9.5 (8.7 to 10.3$)$ & 25.8 (15.0 to 44.4$) ;<0.0005$ \\
\hline Genital & $39 / 32$ & $0.3(0.2$ to 0.5$)$ & $27 / 21$ & $0.4(0.2$ to 0.7$)$ & $12 / 11$ & $0.2(0.1$ to 0.4$)$ & 0.51 (0.23 to 1.13$) ; 0.10$ \\
\hline Other & $51 / 27$ & $0.3(0.2$ to 0.4$)$ & $26 / 11$ & $0.2(0.1$ to 0.4$)$ & $25 / 16$ & $0.3(0.2$ to 0.5$)$ & 1.37 (0.59 to 3.20$) ; 0.46$ \\
\hline Any site† & $1943 / 1049$ & $10.0(9.4$ to 10.6$)$ & $495 / 261$ & 5.1 (4.4 to 5.8$)$ & $1448 / 788$ & $14.6(13.7$ to 15.7$)$ & 2.88 (2.48 to 3.35$) ;<0.0005$ \\
\hline
\end{tabular}

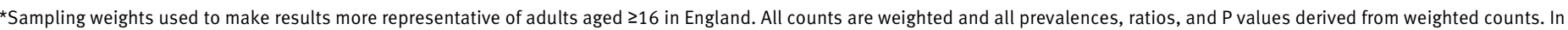

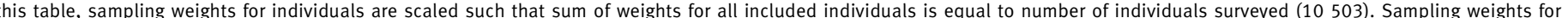

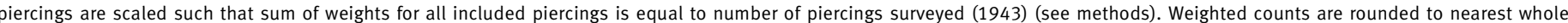
number.

†Includes six piercings for which site was not recorded.

following health problems: none, swelling, bleeding, infection, tear or injury, allergy, other, and don't know. If a health problem was recorded, the respondent was asked "Which, if any, of the following sources of professional help did you use?" To this they were allowed to record one or more of the following sources of professional help: none, piercer, NHS Direct, pharmacist, general practitioner, accident and emergency department, hospital admission, other, and don't know. Respondents answered questions themselves on a laptop computer without having to divulge responses to the interviewer. Interviewers showed the respondent how to use the laptop with a couple of practice questions.

We used sampling weights to make results more representative of adults aged 16 or over in England and of the piercings they have. The research company provided the sampling weights, which we used in all analyses. These weights were based on the national demographic profile of adults in England aged 16 or over. We used demographic variables to weight the sample (sex, working full time or not, with or without children, age group (16-24, 25-34, 35-44, 45-54, 55-64, $\geq 65)$, social grade (AB, C1, C2, D , E) ${ }^{19}$ and region). In an analysis of all individuals surveyed, we standardised weights so that the sum of the weights equalled the total number of all individuals surveyed (10 503). In an analysis of all piercings, we standardised weights so that the sum of the weights equalled the total number of reported piercings (1943). In an analysis of all piercings in 16-24 year olds, we standardised weights so that the sum of the weights equalled the total number of reported piercings in that age group (754).

We based confidence intervals and significance tests on the modified sandwich estimator of variance ${ }^{2021}$ allowing for the clustering of the sample within the primary sampling units and the stratification of the sampling by region. This had the effect of widening confidence intervals and increasing $P$ values. The size of the allowance made depended on the particular analysis. The design effect for the overall prevalence of body piercing was 1.20. All data management and analyses (after we received the data from BMRB) were performed with Stata 8.2 (StataCorp, College Station, TX).

BMRB complies with the Market Research Society's Code of Conduct and guidelines, and is British Standard BS7911/Market Research Quality Standards Association MRQSA certified. All data were managed in accordance with the Data Protection Act 1998.

\section{RESULTS}

In total, 10503 adults aged 16 or over living in England in the period January to March 2005 answered questions about body piercing. We cannot calculate a response rate because we do not know how many approaches led to either a refusal or to no contact being made. Four respondents claimed that they didn't know whether or not they had ever had a body piercing. Of the 1943 piercings recorded, only six had no information about its anatomical site. Three were recorded with no information about who performed the piercing, and three "don't know" responses were recorded to the question regarding whether or not health problems were experienced. Of those reporting health problems, all answered questions about professional help sought.

We estimated that $10 \%$ of adults $(95 \%$ confidence interval $9.4 \%$ to $10.6 \%, 1049 / 10503$ ) have ever had a body piercing (table 1 ). The mean number of piercings per pierced individual was 1.71. Seven individuals reported having had at least 10 piercings.

In each age group piercing was more common in women than men (data not shown) and was about three times more common in women than men overall (table 1). Piercing was much more common in younger age groups (table 1). Indeed there was a steady and marked fall in prevalence with increasing age. Nearly half the women aged 16-24 reported having had a piercing (305/659, 46.2\%, 42.0\% to 50.5\%) (table 1). Piercing was significantly less common in social grades A and B than in lower grades (table 1). Piercing was 
significantly less common in London than in other regions (prevalence ratio $0.68,0.55$ to $0.84 ; \mathrm{P}<0.001$ ) (table 1). Further analysis showed that this could not be explained by differences in age group, sex, or social grade.

Of all 1934 piercings, 33\% were at the navel, followed by nose (19\%), ear (13\%), tongue (9\%), nipple $(9 \%)$, eyebrow $(8 \%)$, lip $(4 \%)$, genitals $(2 \%)$, and some other part of the body $(3 \%)$ (table 2). The anatomical sites used for piercing varied by sex (table 2). In women, the most common piercings were, in order: navel, nose, ear, tongue, eyebrow, nipple, lip; and in men: nipple, eyebrow, ear, tongue, nose, lip, genitals. Thus nipple piercing was the most popular in men, but one of the least popular in women, while navel piercing was by far the most popular in women (accounting for more than a third of all piercings in women) and much rarer in men (table 2). Genital piercing was not popular but is estimated to be about twice as common in men than in women (although small numbers mean that the evidence for this is limited, $\mathrm{P}=0.1$ ) (table 2). All sites of piercing were more common among 16-24 year olds than those who were older; this was particularly the case for lip and tongue piercings (table 3).

Four in five $(1564 / 1943,80 \%)$ piercings were performed in specialist piercing/tattooing shops (table 4), and with certain piercings such as tongue and navel, about $90 \%$ were performed in specialist shops. A worrying $9 \%$ of tongue piercings, however, were performed by "non-specialists." Compared with other types of piercings, piercings of the ears (excluding lobes), nose, lips, and genitals were more likely to be performed by "non-specialists." At each anatomical site, even genital and tongue, several piercings were reported as having been performed by the individuals themselves or by a friend or relative (table 4).

\section{Complications}

In our analysis we first examined all complications together and then only those that resulted in the seeking of further help as an indication of severity. Overall, complications were reported in 533/1940 (27.5\%,
$24.8 \%$ to $30.3 \%$ ) piercings, with problems thought serious enough to seek further help in 250/1940 $(12.9 \%, 10.8 \%$ to $15.2 \%)$. From the data collected it is not possible to tell when piercings were performed or when complications occurred. An analysis of piercings in the group aged 16-24, in whom piercings and subsequent complications are likely to have been in the recent past, provides a more reliable basis for identifying which type of piercing is more likely to result in a complication. In this age group we found slightly higher proportions of piercings in which complications developed and respondents sought further help (table 5).

The most common problems reported with piercings in those aged 16-24 were swelling, infection, and bleeding. Problems were most likely to be reported with tongue piercings $(50 \%)$, followed by piercings of the genitals $(45 \%)$ and nipple (38\%). Help was most likely to be sought for piercings of the genitals $(45 \%)$, followed by the nipple $(25 \%)$ and tongue $(24 \%)$. At the more unusual sites such as genitals, however, the estimated percentage of piercings resulting in a complication is not precise because of the small numbers of piercings identified. Although not significantly different, piercings performed by a friend or relation, a non-specialist shop, or a mobile piercer, seemed more likely to result in a complication than piercings performed in a specialist piercing/tattooing shop (table 5). Serious complications that resulted in a hospital admission were significantly more likely to occur with piercings performed by a non-specialist (4/ $134,3.0 \%, 0.7 \%$ to $11.9 \%$ ) than with piercings performed by someone at a specialist piercing or tattooing shop $(3 / 620,0.5 \%, 0.1 \%$ to $2.0 \%)(\mathrm{P}=0.01)$. Help was sought most often from pharmacists, piercers, and general practitioners. Almost one in every 100 piercings in this age group resulted in a hospital admission.

\section{DISCUSSION}

Cosmetic body piercing is common in England, particularly in young women aged 16-24. Piercing is

Table 3| Prevalence (95\% confidence interval) of ever having had piercing by specific anatomical site by age group (adults aged $\geq 16$ in England)

\begin{tabular}{|c|c|c|c|c|c|c|c|}
\hline & \multicolumn{2}{|c|}{ Adults $\left(n=10503^{\star}\right)$} & \multicolumn{2}{|c|}{ Age $16-24\left(n=1531^{\star}\right)$} & \multicolumn{2}{|c|}{ Age $\geq 25\left(n=8973^{\star}\right)$} & \multirow{2}{*}{$\begin{array}{l}\text { Crude prevalence ratio for } \\
16-24 v \geq 25 \text {; } \mathrm{P} \text { value }\end{array}$} \\
\hline & No pierced & Prevalence (\%) & No pierced & Prevalence (\%) & No pierced & Prevalence (\%) & \\
\hline Ear (not lobe) & 185 & $1.8(1.5$ to 2.1$)$ & 77 & $5.0(3.9$ to 6.4$)$ & 108 & $1.2(1.0$ to 1.5$)$ & 4.15 (3.08 to 5.61$) ;<0.0005$ \\
\hline Eyebrow & 140 & $1.3(1.1$ to 1.6$)$ & 72 & $4.7(3.7$ to 6.0$)$ & 68 & 0.8 (0.6 to 1.0$)$ & 6.26 (4.43 to 8.85$) ;<0.0005$ \\
\hline Nose & 316 & $3.0(2.7$ to 3.4$)$ & 93 & $6.1(4.9$ to 7.4$)$ & 223 & $2.5(2.2$ to 2.8$)$ & 2.44 (1.94 to 3.06$) ;<0.0005$ \\
\hline Lip & 61 & $0.6(0.4$ to 0.8$)$ & 41 & 2.7 (1.9 to 3.8$)$ & 20 & $0.2(0.1$ to 0.3$)$ & 12.40 (7.13 to 21.57$) ;<0.0005$ \\
\hline Tongue & 156 & $1.5(1.3$ to 1.7$)$ & 100 & 6.5 (5.3 to 8.0$)$ & 56 & $0.6(0.5$ to 0.8$)$ & 10.49 (7.57 to 14.55$) ;<0.0005$ \\
\hline Nipple & 143 & $1.4(1.1$ to 1.6$)$ & 53 & $3.5(2.6$ to 4.7$)$ & 90 & $1.0(0.8$ to 1.2$)$ & 3.45 (2.40 to 4.95$) ;<0.0005$ \\
\hline Navel & 529 & $5.0(4.6$ to 5.5$)$ & 226 & 14.8 (13.0 to 16.8$)$ & 303 & 3.4 (3.0 to 3.8$)$ & 4.38 (3.71 to 5.17 ); $<0.0005$ \\
\hline Genital & 32 & $0.3(0.2$ to 0.5$)$ & 12 & $0.8(0.4$ to 1.5$)$ & 20 & $0.2(0.1$ to 0.4$)$ & 3.49 (1.55 to 7.88$) ; 0.001$ \\
\hline Other & 27 & $0.3(0.2$ to 0.4$)$ & 10 & 0.7 (0.3 to 1.2$)$ & 17 & $0.2(0.1$ to 0.3$)$ & 3.45 (1.49 to 7.98$) ; 0.002$ \\
\hline Any of above & 1049 & $10.0(9.4$ to 10.6$)$ & 419 & $27.4(24.8$ to 30.0$)$ & 630 & $7.0(6.5$ to 7.6$)$ & 3.89 (3.47 to 4.38 ); $<0.0005$ \\
\hline
\end{tabular}

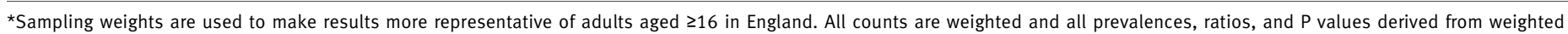

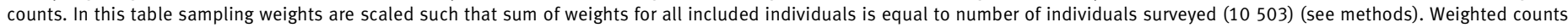
are rounded to nearest whole number. 
about three times more common in women than men in all age groups. The clear trend in prevalence of piercing by age group in both sexes confirms that piercing is favoured more by the young and is a fairly recent phenomenon. In those aged 16-24, complications were reported in almost a third of piercings, with about one in seven resulting in difficulties considered problematic enough to require professional help. Help was most often sought from pharmacists, piercers, or general practitioners, with almost one in 100 piercings resulting in a hospital admission.

The choice of anatomical site for piercing clearly varies by sex. In our survey, women particularly favoured navel, nose, ear, and tongue piercings, whereas men favoured nipple, eyebrow, ear, and tongue piercings. Nipple, eyebrow, and genital piercings were more common in men than women. Although not much favoured by men, navel piercings were by far the most common piercing, accounting for $33 \%(639 / 1943)$. Other studies have shown sex differences in choice of piercing site, although the most popular sites vary slightly by population studied. All piercings were more common in young people, but the fact that piercings of the lip and tongue were particularly popular in those aged 16-24 suggests that oral piercings are a more recent fashion and that people might be becoming more adventurous. That piercing was less common in London than other regions might be related to ethnic, cultural, or religious differences.

About a third of all complications were associated with navel piercings, the most common type of piercing. Tongue piercings, however, most often resulted in a complication (usually swelling). About a half of tongue piercings resulted in a complication and about a quarter resulted in help being sought. Intimate (nipple and genital) piercings were less common but the chances of a complication occurring were relatively high (about a quarter of nipple piercings and about a half of all genital piercings resulting in help being sought). A high level of complications with such piercings has been reported by others. ${ }^{22}$ Interestingly, help was sought in a greater proportion of complications at the ear, nipple, and genital as opposed to other sites. This could indicate that, should a complication occur at these sites, there is a greater chance of it being considered serious by the individual concerned.

Although most problems associated with piercing are usually minor and self limiting, some complications are serious and can be fatal. There is some evidence to support the concerns raised about the transmission of bloodborne viruses through body piercing. ${ }^{23}$ Our study was not designed to identify such rare complications, but piercers, people choosing to be pierced, and healthcare providers need to be aware of the possible serious negative outcomes of body piercing.

Most piercings were performed in specialist piercing or tattooing shops, although about $20 \%$ were performed outside of these settings. Self piercings were reported at every anatomical site we asked about, even the tongue. Piercings in settings other than specialist piercing/tattooing shops were more likely to result in a complication for which help was sought $(22 \%$ of piercings by non-specialists compared with $14 \%$ of piercings by specialists, $\mathrm{P}=0.13$ ) and were significantly more likely to result in a complication requiring a hospital admission (3\% of piercings by non-specialists compared with $0.5 \%$ of piercings by specialists, $\mathrm{P}=0.01$ ).

Our estimate of prevalence of body piercing overall and our finding that piercing was more common in women than men and in younger age groups support those of similar studies carried out in other developed countries. ${ }^{1-13}$ Our study supports and extends the information presented by Laumann and Derick on the proportion of piercings in which complications developed, and the proportion of piercings performed by different providers. ${ }^{13}$

\section{Limitations}

Our study might have been subject to some selection bias as the selection of the sample was not truly random. Moreover, it is not known how many approaches led to a refusal or no contact being made, potentially

\begin{tabular}{|c|c|c|c|c|c|c|c|}
\hline & Respondent & Friend or relation & $\begin{array}{c}\text { Specialist } \\
\text { piercing shop }\end{array}$ & Another shop & Mobile piercer & Other & $\begin{array}{l}\text { No of piercings } \\
\text { (weighted*) }\end{array}$ \\
\hline Ear & $35(14.2,9.1$ to 21.5$)$ & $13(5.4,2.6$ to 10.7$)$ & $152(61.8,52.6$ to 70.3$)$ & $31(12.6,8.7$ to 18.0$)$ & $8(3.4,1.2$ to 8.8$)$ & $6(2.5,1.0$ to 6.2$)$ & 246 \\
\hline Eyebrow & $11(6.8,3.4$ to 13.0$)$ & $10(5.8,2.7$ to 12.0$)$ & $136(82.7,75.0$ to 88.4$)$ & $5(3.0,1.2$ to 7.4$)$ & $2(1.4,0.3$ to 5.3$)$ & $1(0.3,0.0$ to 2.4$)$ & 164 \\
\hline Nose & $19(5.1,3.1$ to 8.2$)$ & $12(3.1,1.7$ to 5.6$)$ & $257(69.7,63.5$ to 75.2$)$ & $67(18.1,13.5$ to 23.9$)$ & $8(2.1,0.9$ to 4.6$)$ & $7(1.9,0.9$ to 4.0$)$ & 368 \\
\hline Lip & $7(8.5,3.8$ to 17.8$)$ & $6(8.1,3.3$ to 18.8$)$ & $56(71.5,56.1$ to 83.1$)$ & $2(2.8,0.7$ to 112$)$ & 0 & $7(9.1,4.1$ to 19.0$)$ & 78 \\
\hline Tongue & $2(1.2,0.3$ to 5.0$)$ & $5(2.5,1.0$ to 6.2$)$ & $167(91.5,85.9$ to 95.0$)$ & $9(4.8,2.5$ to 8.9$)$ & 0 & 0 & 183 \\
\hline Nipple & $10(5.7,3.0$ to 10.6$)$ & $8(4.5,1.9$ to 10.5$)$ & $146(84.3,76.3$ to 89.9$)$ & $6(3.4,1.5$ to 7.4$)$ & $4(2.2,0.7$ to 6.8$)$ & 0 & 173 \\
\hline Navel & $13(2.0,1.1$ to 3.5$)$ & $8(1.2,0.6$ to 2.3$)$ & $581(90.7,87.6$ to 93.1$)$ & $36(5.6,3.7$ to 8.3$)$ & $2(0.4,0.1$ to 1.5$)$ & $1(0.2,0.0$ to 1.2$)$ & 641 \\
\hline Genital & $1(3.4,0.5$ to 20.9$)$ & $5(13.0,4.9$ to 30.1$)$ & $30(76.4,59.5$ to 87.7$)$ & $2(4.6,1.1$ to 17.6$)$ & $1(2.7,0.4$ to 16.9$)$ & 0 & 39 \\
\hline Other & $6(12.0,4.2$ to 29.6$)$ & 0 & $40(77.6,58.7$ to 89.4$)$ & $1(1.1,0.1$ to 7.6$)$ & 0 & $5(9.4,3.0$ to 25.9$)$ & 51 \\
\hline Total & $104(5.3,3.9$ to 7.2$)$ & $66(3,2.5$ to 4.6$)$ & $1564(80.4,77.4$ to 83.2$)$ & $158(8.1,6.6$ to 9.9$)$ & $25(1.3,0.8$ to 2.2$)$ & $27(1.4,0.9$ to 2.2$)$ & 1943 \\
\hline
\end{tabular}

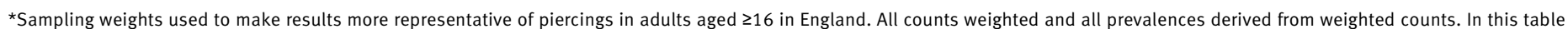

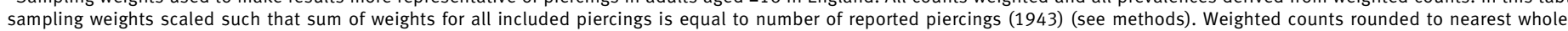
number. 
introducing a further selection bias to our results. Our estimates could have been affected if individuals with body piercings were more or less likely to be at home or more or less willing to participate in research. We consider that the sampling method and corrective weighting used, however, produced good estimates for all adults and all body piercings (excluding earlobe piercings) in the population aged 16 or over and living in England.

Data were collected with a self completed questionnaire to avoid embarrassment with regard to intimate piercings, but some recall or response bias remains possible. The maximum number of piercings recordable for each individual was 10 . Of the seven individuals who reported at least 10 , some bias could have occurred in their choice of which piercings to report. Respondents were limited to fixed categories of response and their responses were not verified. The detail of each complication was not captured and there could have been some misclassification, such as confusion between infection and allergy.

We did not collect data on the date of piercing and the date of any complications so it was impossible to estimate a proper risk. But piercings and complications in those aged 16-24 will have occurred in the fairly recent past and restricting an analysis of complications to these 754 piercings is a more reliable basis for identifying which type of piercing is more likely to result in a complication.

\section{Conclusions}

The findings of our study are important because they provide background information showing that piercing is common, particularly in young women; that

Table 5 | Percentage of piercings (in those aged 16-24 only) resulting in complication and resulting in complication for which professional help was sought

\begin{tabular}{|c|c|c|c|}
\hline & No of piercings (weighted) & $\begin{array}{l}\text { No }(\%, 95 \% \mathrm{Cl}) \text { with complications } \\
\text { (weighted) }\end{array}$ & $\begin{array}{l}\text { No }(\%, 95 \% \mathrm{Cl}) \text { with help sought } \\
\text { (weighted) }\end{array}$ \\
\hline Overall & 754 & $233(31.0,26.7$ to 35.5$)$ & $115(15.2,11.8$ to 19.5$)$ \\
\hline \multicolumn{4}{|l|}{ Type of complication: } \\
\hline Swelling & 754 & $116(15.4,12.7$ to 18.6$)$ & $47(6.3,4.6$ to 8.5$)$ \\
\hline Infection & 754 & $73(9.7,7.3$ to 12.9$)$ & $51(6.8,4.6$ to 10.0$)$ \\
\hline Bleeding & 754 & $65(8.6,6.4$ to 11.3$)$ & $31(4.1,2.6$ to 6.5$)$ \\
\hline Other & 754 & $19(2.5,1.4$ to 4.3$)$ & $8(1.1,0.4$ to 2.7$)$ \\
\hline Allergy & 754 & $12(1.6,0.8$ to 3.3$)$ & $11(1.5,0.7$ to 3.1$)$ \\
\hline Tear or injury & 754 & $10(1.3,0.7$ to 2.4$)$ & $4(0.5,0.2$ to 1.3$)$ \\
\hline \multicolumn{4}{|l|}{ Anatomical site: } \\
\hline Navel & 242 & $73(30.2,24.1$ to 37.2$)$ & $36(14.8,10.4$ to 20.7$)$ \\
\hline Tongue & 105 & $53(50.1,40.2$ to 59.9$)$ & $26(24.3,16.4$ to 34.6$)$ \\
\hline Nose & 103 & $25(24.0,16.2$ to 34.0$)$ & $9(8.9,4.1$ to 18.3$)$ \\
\hline Ear (excluding lobe) & 92 & $21(22.6,14.5$ to 33.4$)$ & $13(14.4,8.0$ to 24.5$)$ \\
\hline Eyebrow & 73 & $21(29.2,19.4$ to 41.3$)$ & $4(5.8,2.2$ to 14.4$)$ \\
\hline Nipple & 60 & $23(38.3,24.8$ to 53.9$)$ & $15(24.7,13.9$ to 40.0$)$ \\
\hline Lip & 48 & $10(20.5,9.2$ to 39.8$)$ & $5(11.2,3.4$ to 31.3$)$ \\
\hline Other & 18 & $2(11.4,3.3$ to 32.4$)$ & $1(3.4,0.4$ to 22.1$)$ \\
\hline Genital & 14 & $6(44.6,23.7$ to 67.5$)$ & $6(44.6,23.7$ to 67.5$)$ \\
\hline \multicolumn{4}{|l|}{ Type of piercer: } \\
\hline Specialist piercing shop & 620 & $185(29.8,25.5$ to 34.4$)$ & $85(13.7,10.6$ to 17.7$)$ \\
\hline Another shop & 56 & $26(45.6,31.9$ to 60.1$)$ & $17(29.8,17.7$ to 45.7$)$ \\
\hline Respondent & 44 & $8(19.2,8.9$ to 36.5$)$ & $3(7.7,2.4$ to 22.1$)$ \\
\hline Friend or relation & 21 & $11(52.3,25.4$ to 78.0$)$ & $6(27.2,7.1$ to 64.4$)$ \\
\hline Other & 7 & $2(26.6,4.0$ to 75.8$)$ & $2(26.6,4.0$ to 75.8$)$ \\
\hline Mobile piercer & 6 & $2(34.2,5.4$ to 82.7$)$ & $2(34.2,5.4$ to 82.7$)$ \\
\hline \multicolumn{4}{|l|}{ Help sought from: } \\
\hline Piercer & 754 & - & $35(4.4,3.1$ to 6.9$)$ \\
\hline NHS direct & 754 & - & $7(0.9,0.4$ to 2.0$)$ \\
\hline Pharmacist & 754 & - & $38(5.1,3.3$ to 7.7$)$ \\
\hline General practitioner & 754 & - & $23(3.0,1.8$ to 4.8$)$ \\
\hline$A \& E$ & 754 & 一 & $4(0.6,0.1$ to 2.3$)$ \\
\hline Hospital admission & 754 & - & $7(0.9,0.3$ to 3.2$)$ \\
\hline Other & 754 & - & $13(1.8,0.9$ to 3.3$)$ \\
\hline
\end{tabular}

$\mathrm{A} \& \mathrm{E}=$ accident and emergency department.

*Sampling weights used to make results more representative of piercings in adults aged 16-24 in England. All counts weighted and all prevalences derived from weighted counts. In this table sampling weights are scaled such that sum of weights for all included piercings is equal to number of reported piercings in 16-24 year olds (754) (see methods). Weighted counts rounded to nearest whole number. 


\section{WHAT IS ALREADY KNOWN ON THIS TOPIC}

Complications from body piercing are common

Published estimates of prevalence and the level of complications vary widely depending on the populations studied and definitions used

\section{WHAT THIS STUDY ADDS}

About one in 10 of the adult population of England has had a body piercing at a site other than the earlobe

Almost half of women aged 16-24 have had such a piercing

In those aged 16-24, health problems occurred with about a third of piercings and further help was sought in about one in seven, leading to hospital admission in about one in 100

complications are common; and that health service providers are often called on to help. If piercing remains fashionable, almost half the female population might eventually have had a body piercing at a site other than the earlobe. Even if serious complications are rare, the popularity of the practice and the fact that complications can occur long after the actual piercing, might place a considerable burden on health services for many years. Health professionals need to be aware of the potential complications of body piercing and the appropriate management. More research is needed to determine which factors increase the risk of complications so that this information can be used to raise awareness in piercers, their clients, and health services and to improve the safety of body piercing.

We thank the British Market Research Bureau (BMRB) for its assistance in preparing the questionnaire, obtaining the sample, and collecting the data. Contributors: $\mathrm{AB}$ participated in the design, analysis and interpretation of the study, and drafted the paper. FN participated in the design, analysis, and interpretation of the study, commented on the drafts, and is guarantor. TN participated in the design and interpretation of the study, performed the statistical analyses, and commented on the drafts. NDN participated in the design, analysis, and interpretation of the study and commented on the drafts. All authors saw and approved the final version. Funding: Department of Health.

Competing interests: NDN has acted as a paid hygiene consultant to acupuncturists and manufacturers of ear piercing equipment and an unpaid hygiene consultant to tattooists and beauty therapists. He has also acted as an expert witness in judicial cases concerned with the hygiene of skin piercing.

Ethical approval: Not required
Provenance and peer review: Not commissioned; externally peer reviewed.

1 House of Commons official report (Hansard). 1999 May 12:col 284-90.

2 Gould M. Warning of disease risk on body art. Observer 2003 Sep 14.

3 Stirn A. Body piercing: medical consequences and psychological motivations. Lancet 2003;361:1205-15.

4 Theodossy T. A complication of tongue piercing. A case report and review of the literature. Br Dent J 2003;194:551-2.

5 Armstrong ML, Roberts AE, Owen DC, Koch JR. Contemporary college students and body piercing. J Adolesc Health 2004;35:58-61.

6 Roberts TA, Auinger P, Ryan SA. Body piercing and high-risk behavior in adolescents. J Adolesc Health 2004;34:224-9.

7 Mayers LB, Judelson DA, Moriarty BW, Rundell KW. Prevalence of body art (body piercing and tattooing) in university undergraduates and incidence of medical complications. Mayo Clin Proc 2002;77:29-34.

8 Willmott FE. Body piercing: lifestyle indicator or fashion accessory? Int I STD AIDS 2001;12:358-60.

9 Brooks TL, Woods ER, Knight JR, Shrier LA. Body modification and substance use in adolescents: is there a link? J Adolesc Health 2003;32:44-9.

10 Carroll ST, Riffenburgh RH, Roberts TA, Myhre EB. Tattoos and body piercings as indicators of adolescent risk-taking behaviors. Pediatrics 2002;109:1021-7.

11 Makkai T, McAllisterl. Prevalence of tattooing and body piercing in the Australian community. Commun Dis Intell 2001;25:67-72.

12 Stirn A, Hinz A, Brahler E. Prevalence of tattooing and body piercing in Germany and perception of health, mental disorders, and sensation seeking among tattooed and body-pierced individuals. J Psychosom Res 2006;60:531-4.

13 Laumann AE, Derick AJ. Tattoos and body piercings in the United States: a national data set. J Am Acad Dermatol 2006;55:413-21.

14 Simplot TC, Hoffman HT. Comparison between cartilage and soft tissue ear piercing complications. Am / Otolaryngol 1998;19:305-10.

15 Greif J, Hewitt W, Armstrong ML. Tattooing and body piercing. Body art practices among college students. Clin Nurs Res 1999;8:368-85.

16 Hanif J, Frosh A, Marnane C, Ghufoor K, Rivron R, Sandhu G. Lesson of the week: "high" ear piercing and the rising incidence of perichondritis of the pinna. BMJ 2001;322:906-7.

17 Benon L, Silverwood A, Horth C, Johnson A, Dineen J. A piercing issue. Environ Health / 1999;Oct:316-8.

18 Whittle JG, Lamden KH. Lip and tongue piercing: experiences and views of general dental practitioners in South Lancashire. Prim Dent Care 2004;11:92-6.

19 Market Research Society. Occupation groupings: a job dictionary. 6th ed. London: Market Research Society, 2006.

20 Williams RL. A note on robust variance estimation for clustercorrelated data. Biometrics 2000;56:645-6.

21 Wooldridge JM. Econometric analysis of cross section and panel data. Cambridge, MA: MIT Press, 2002.

22 Caliendo C, Armstrong ML, Roberts AE. Self-reported characteristics of women and men with intimate body piercings. J Adv Nurs 2005;49:474-84.

23 Hayes MO, Harkness GA. Body piercing as a risk factor for viral hepatitis: an integrative research review. Am J Infect Control 2001;29:271-4.

Accepted: 9 April 2008 